\title{
Successful treatment of a genetic childhood ataxia due to riboflavin transporter deficiency
}

\author{
Judy Fan ${ }^{1}$ and Brent L. Fogel ${ }^{1,2^{*}}$
}

\begin{abstract}
Background: Riboflavin transporter deficiency (Brown-Vialetto-Van Laere syndrome) is a rare recessive neurodegenerative disorder that can present with gait ataxia, primarily due to sensory neuropathy as well as cerebellar involvement. Although sensorineural hearing loss, bulbar palsy, and optic atrophy are typical, presentation may be variable and an atypical condition may be difficult to recognize clinically.

Case presentation: Here we report a patient presenting at age 8 with progressive ataxia since the age of 2.5 years with cerebellar atrophy and peripheral polyneuropathy. Whole exome sequencing identified a known pathogenic mutation in the SLC52A2 gene consistent with a diagnosis of Brown-Vialetto-Van Laere syndrome despite the absence of common symptoms including motor neuropathy, bulbar palsy, optic atrophy, and sensorineural hearing loss. High-dose riboflavin therapy was initiated, symptoms stabilized, metabolic abnormalities resolved, and the patient is doing well with a near-normal examination at age 15.

Conclusions: Riboflavin transporter deficiency can be fatal if left untreated. The excellent outcome of this case illustrates the importance of identifying this potentially treatable neurologic condition. In this patient, clinical diagnosis was limited by an atypical presentation lacking several common features which was overcome through the use of genomic sequencing identifying the pathogenic mutation enabling correct diagnosis and subsequent treatment. Riboflavin transporter deficiency should be considered early in the diagnostic evaluation as a treatable form of ataxia in children, even if patients lack typical features.
\end{abstract}

Keywords: Cerebellar Ataxia, Spinocerebellar Ataxia, SLC52A2, Riboflavin, Neurogenetics

\section{Background}

Riboflavin transporter deficiency, also known as Brown -Vialetto-Van Laere syndrome, is a rare autosomal recessive neurodegenerative disorder that can include progressive motor and sensory neuropathy, gait ataxia (typically due to sensory neuropathy), sensorineural hearing loss, bulbar palsy, and optic atrophy [1]. Respiratory insufficiency can lead to ventilator dependence and the outcome can be fatal in childhood [1,2]. The disease is caused by defects in the human riboflavin transporters

\footnotetext{
*Correspondence: bfogel@ucla.edu

${ }^{1}$ Program in Neurogenetics, Department of Neurology, David Geffen School of Medicine, University of California Los Angeles, Los Angeles, CA 90095, USA ${ }^{2}$ Department of Human Genetics, David Geffen School of Medicine, University of California Los Angeles, 695 Charles E. Young Drive South, Gonda Room 1206, Los Angeles, CA 90095, USA
}

RFVT2 and RVFT3, encoded by the SLC52A2 and $S C L 52 A 3$ genes, respectively $[1,2]$. Previous reports have noted that response to high-dose riboflavin supplementation can be life-saving and has included stabilization of function, normalization of metabolic abnormalities and audiometry, and improvement in growth, muscle tone, pulmonary function, and visual evoked potentials in some patients [1-4]. Here we report a case of a child originally diagnosed with cerebellar ataxia found to have mutation of SLC52A2 and successfully treated with high-dose riboflavin.

\section{Case presentation}

The patient was born to consanguineous parents (second cousins) of Lebanese descent. She walked at 18 months, but unsteadily, with toe walking and minimal knee bending. Development was otherwise normal. At

(C) The Author(s). 2018 Open Access This article is distributed under the terms of the Creative Commons Attribution 4.0 International License (http://creativecommons.org/licenses/by/4.0/), which permits unrestricted use, distribution, and 
the age of 2.5 years, difficulties with balance and coordination were noted and a neurological examination diagnosed her with ataxia. An MRI confirmed cerebellar atrophy, predominantly of the vermis, and she was diagnosed with cerebellar ataxia. At age 4.5 years she was noted to have scoliosis, which was treated with a brace. Genetic testing for common spinocerebellar ataxias, including SCA1, SCA2, SCA3, SCA6, SCA7, and Friedreich ataxia, was negative [5]. Additional single gene testing was performed for rarer forms of spinocerebellar ataxia as well as for Charcot-Marie-Tooth disease and this was also negative. Basic metabolic testing was normal and included levels of lactate, pyruvate, coenzyme-Q10, and fasting glucose.

Symptoms continued to worsen and she was seen for evaluation at our tertiary referral center at age 8 years. Although she experienced regular falls, she was active and able to ride a bike with training wheels. Physical examination revealed appendicular and gait ataxia as well as a multimodal, predominantly sensory, peripheral neuropathy, with areflexia and upgoing toes. Nerve conduction study showed absent sensory responses but normal motor responses in the limbs. Audiology evaluation revealed no sensorineural hearing loss although she was later diagnosed with an auditory processing disorder at 9 years old. There was no other family history of neurological disease. Basic laboratory testing remained normal although very long chain fatty acids showed mildly elevated phytanic acid $3.95 \mu \mathrm{mol} / \mathrm{L}(0.37-3.46 \mu \mathrm{mol} / \mathrm{L})$ and pristanic acid $0.31 \mu \mathrm{mol} / \mathrm{L}(\leq 0.28 \mu \mathrm{mol} / \mathrm{L})$ so a metabolic disorder was considered and genomic sequencing was performed. Whole exome sequencing revealed a homozygous c.916G > A (p.Gly306Arg) variant in the SLC52A2 gene [6]. Each of her parents was found to be a heterozygous carrier. This is a known pathogenic variant thought to be a founder mutation in the Lebanese population [4].

The patient was started on high-dose riboflavin therapy at $4.5 \mathrm{mg} / \mathrm{kg} /$ day at age 9 years. Plasma riboflavin levels ranged between $7.6-27.5 \mathrm{nmol} / \mathrm{L}$ (normal 6.2$39.0 \mathrm{nmol} / \mathrm{L}$ ). Her scale for the assessment and rating of ataxia (SARA) score at presentation was 9.5 (severity range $0-40$ ) and improved to 8 within the first year of treatment. Plasma acylcarnitine profile and urine organic acid levels were monitored throughout treatment and initially showed mild nonspecific abnormalities that subsequently normalized with treatment (see Additional file 1: Table S1). Her riboflavin dose was titrated to a peak of $13 \mathrm{mg} / \mathrm{kg} /$ day given the persistent nonspecific elevations seen on metabolic testing but was later reduced to $10.5 \mathrm{mg} / \mathrm{kg} / \mathrm{day}$ after gastrointestinal upset led to noncompliance and a worsening of symptoms. At age 15 years she is active, participating in sports, and otherwise healthy with a SARA score of 3.0.

\section{Discussion and conclusions}

Riboflavin transporter deficiency is a rare neurodegenerative condition that, if left untreated, can lead to a fatal outcome. A recent review describing 27 patients with RVFT2 deficiency reported that high-dose riboflavin supplementation can often lead to stabilization $(8 / 28$, $30 \%)$, if not improvement (12/27, $44 \%)$, of symptoms [2]. This included benefits in muscle tone, gait, pulmonary function, and fatigability, with normalization of metabolic abnormalities and audiometry [2, 4]. There have also been individual case reports of severe presentations showing remarkable improvement on high-dose riboflavin $[7,8]$. The pathophysiology of this condition is still unclear, however, and optimal dosing of riboflavin is unknown $[1,2]$.

In the majority of patients with riboflavin transporter deficiency, a sensory gait ataxia occurs due to sensory neuropathy $[1,2]$. There are, however, descriptions of patients with SLC52A2 mutations and cerebellar involvement $[1,9]$. It may be difficult to distinguish the two in young children. Here we report a patient originally diagnosed with cerebellar atrophy and a corresponding ataxia (likely due to a combination of cerebellar and sensory dysfunction) found to have riboflavin transporter deficiency syndrome caused by mutation of the SLC52A2 gene although lacking many of the common elements of the classic disorder. Given that the prevalence and expressivity of this disease is currently unknown, atypical or mild cases could be missed in the early evaluation where treatment with riboflavin could be most beneficial. This case serves as an illustration of the importance of recognizing these patients early as a very successful outcome was attained with high-dose riboflavin supplementation over 6 years. Therefore riboflavin transporter deficiency should be considered early in the diagnostic evaluation as a treatable form of ataxia in children, even if patients lack typical features such as motor neuropathy, sensorineural hearing loss, or optic atrophy. Genomic sequencing may be of particular value in these instances as it surveys the entire human genome and, unlike limited gene panels, is unbiased toward disorders with atypical or unusual presentations $[6,10]$.

\section{Additional file}

Additional file 1: Table S1. Laboratory testing. (DOCX $20 \mathrm{~kb}$ )

\section{Funding}

This work was supported in part by the National Institute for Neurological Disorders and Stroke (grant R01NS082094 to Dr. Fogel).

Availability of data and materials

The datasets generated and/or analyzed during the current study are not publicly available as they could compromise the anonymity of the subject but specific data elements may be available from the corresponding author on reasonable request. 


\section{Authors' contributions}

BLF performed all clinical work as well as conceived and designed the project. JF and BLF wrote the manuscript and were responsible for its review and critique. Both authors read and approved the final manuscript.

\section{Ethics approval and consent to participate}

The parents of the patient enrolled in this study provided written informed consent. All methods in this study were approved by the institutional review board of the University of California at Los Angeles.

\section{Consent for publication}

The parents of the patient enrolled in this study provided written consent for anonymous/de-identified presentation and/or publication of her case.

\section{Competing interests}

The authors declare that they have no competing interests.

\section{Publisher's Note}

Springer Nature remains neutral with regard to jurisdictional claims in published maps and institutional affiliations.

Received: 3 September 2018 Accepted: 3 October 2018

Published online: 20 October 2018

\section{References}

1. Manole A, Houlden H. In: Adam MP, Ardinger HH, Pagon RA, Wallace SE, LH B, Stephens K, et al., editors. Riboflavin transporter deficiency neuronopathy. Seattle: GeneReviews((R)); 2015.

2. Jaeger B, Bosch AM. Clinical presentation and outcome of riboflavin transporter deficiency: mini review after five years of experience. J Inherit Metab Dis. 2016;39(4):559-64.

3. Bosch AM, Abeling NG, ljlst L, Knoester H, van der Pol WL, Stroomer AE, et al. Brown-Vialetto-Van Laere and Fazio Londe syndrome is associated with a riboflavin transporter defect mimicking mild MADD: a new inborn error of metabolism with potential treatment. J Inherit Metab Dis. 2011; 34(1):159-64.

4. Foley AR, Menezes MP, Pandraud A, Gonzalez MA, Al-Odaib A, Abrams AJ et al. Treatable childhood neuronopathy caused by mutations in riboflavin transporter RFVT2. Brain. 2014;137(Pt 1):44-56.

5. Fogel BL. Childhood cerebellar ataxia. J Child Neurol. 2012;27(9):1138-45.

6. Fogel BL, Lee H, Deignan JL, Strom SP, Kantarci S, Wang X, et al. Exome sequencing in the clinical diagnosis of sporadic or familial cerebellar ataxia. JAMA Neurol. 2014;71(10):1237-46.

7. Bashford JA, Chowdhury FA, Shaw CE. Remarkable motor recovery after riboflavin therapy in adult-onset Brown-Vialetto-Van Laere syndrome. Pract Neurol. 2017;17(1):53-6.

8. Forman EB, Foley AR, King MD. Dramatic improvement of a rare syndrome with high dose riboflavin treatment. Pediatr Neurol. 2018

9. Guissart C, Drouot N, Oncel I, Leheup B, Gershoni-Barush R, Muller J, et al. Genes for spinocerebellar ataxia with blindness and deafness (SCABD/ SCAR3, MIM\# 271250 and SCABD2). Eur J Hum Genet. 2016;24(8):1154-9.

10. Fogel BL, Satya-Murti S, Cohen BH. Clinical exome sequencing in neurologic disease: AAN model coverage policy. Neurol Clin Pract. 2016;6(2):164-76.

Ready to submit your research? Choose BMC and benefit from:

- fast, convenient online submission

- thorough peer review by experienced researchers in your field

- rapid publication on acceptance

- support for research data, including large and complex data types

- gold Open Access which fosters wider collaboration and increased citations

- maximum visibility for your research: over $100 \mathrm{M}$ website views per year

At $\mathrm{BMC}$, research is always in progress.

Learn more biomedcentral.com/submissions 